\title{
Epistemology and economics
}

\author{
Jeffrey Helzner
}

Received: 19 July 2012 / Accepted: 19 July 2012 / Published online: 2 October 2012

(C) Springer Science+Business Media Dordrecht 2012

On April 14th and 15th of 2010 the Synthese Conference on Epistemology and Economics was held at Columbia University in the City of New York. The conference included eleven talks: five invited, five contributed, and one by the winner of the Synthese Distinguished Paper Award. It is not easy to pull off a conference of this sort, especially in a place like New York where the cost of doing business is significant, but all of the reports that I have received suggest that the conference was a great success. I would like to thank the following people for their hard work: the Synthese Editors-in-Chief at the time of the conference, Johan van Benthem, Vincent Hendricks, and John Symons; my fellow members of the Local Organizing Committee, John Collins, Haim Gaifman, and Philip Kitcher; Ties Nijssen and Ingrid van Laarhoven at Springer; Stacey Quartaro, Department Administrator for the Department of Philosophy at Columbia, and Achille Varzi, Chair of the Department of Philosophy at Columbia.

The papers in this volume represent some of the work that was presented at the conference. Before turning attention to the specific papers in this volume, it seems appropriate to make some general comments on the conference theme since it might not be clear what sorts of philosophically interesting relations exist between epistemology and economics. After all, epistemology is often identified with attempts to analyze terms like knows and believes, while much of classical economics (e.g., consumer theory, the theory of the firm) can be understood as being about rational agents and the various equilibria that could result from their interactions. The following is a brief survey of just some of the philosophically interesting relations between epistemology and economics:

\footnotetext{
J. Helzner ( $\square)$

Columbia University, New York, USA

e-mail: jh2239@columbia.edu
} 
- Clarifying terms like knows and believes in the context of theories of rational choice - One of the most fundamental assumptions in contemporary theories of rational choice is that the agent ought to restrict its selection to those available alternatives that are admissible relative to its beliefs and desires. According to subjective expected utility theory - which, at least in the context of deliberate decision making, is arguably the most widely endorsed standard of individual rationality - the beliefs and desires of the rational agent are representable by a probability measure and a cardinal utility, respectively. According to some views, this subjective (or personal) probability measure tells the entire story when it comes to the agent's epistemic state (Jeffrey 1992). Others maintain that there is more to the agent's epistemic state than just the credences (or degrees of belief) that are supposed to be represented by the agent's subjective probability (Levi 1980).

- Rational choice and psychology - Attempts to clarify epistemic notions through their role in a theory of rational choice can lead to familiar philosophical issues e.g., such as the relationship between is and ought - in the context of discussions concerning the rationality of human agents. Consider decision problems of the sort that were made famous by Ellsberg (1961). There is plenty of empirical evidence to suggest that a significant number of people violate the requirements of subjective expected utility theory when confronted with such decision problems. Are all of these people irrational? Perhaps some of these violators are irrational, but what if one of them were to show no interest in a cost-free "replay" of the decision problem at issue after being informed that they had violated the requirements of subjective expected utility theory in their previous attempt. Should we always classify such an individual as irrational? Some people, including Ellsberg, do not think so (Levi 1974; Gardenfors and Sahlin 1982). Of course all of this is consistent with the hypothesis that some of the violations that have been observed in connection with such decision problems should be classified as irrational. Such hypotheses help to motivate research programs that are aimed at providing psychological accounts of systematic deviations from the familiar standards of rationality, e.g., versions of the expected utility hypothesis. According to the influential heuristics and biases program that was initiated by Tversky and Kahneman (1974), such deviations can be understood as being the result of cognitive illusions that can be predicted in light of the kinds of operations that are supposed to inform the relevant judgments, e.g., judgments concerning the various uncertainties involved in the decision problem. The growing field of behavioral economics explores the relevance of such research for economists.

- Belief revision - If we think of the agent's beliefs as something that it uses as input to some goal-directed reasoning, then perhaps there are occasions when that input no longer serves the goals to which that reasoning is directed and, furthermore, that the agent itself recognizes that this is so. If there are such occasions, then perhaps among them are those in which the agent has an option to modify this input. An agent who is confronted with such a situation faces a sort of cognitive decision problem, e.g., how should its beliefs be modified in light of certain goals? What standards of rationality should be applied in the context of such cognitive decision problems? Are such standards significantly different 
from the standards of practical rationality that are often assumed by economists (Rott 2004)?

- Interactive epistemology - The influence of Hintikka's analysis of knowledge and belief (Hintikka 1962) is apparent in much of the contemporary work in formal epistemology. That analysis can be taken as the basis for a study of the kind of autoepistemological issues that were considered by G.E. Moore. While a great deal of work has been done in that direction, it is clear that much of the recent work in epistemic logic concerns interactions within a community of knowers (believers). Robert Stalnaker, in a recent interview, offered the following remarks in connection with the suggested developments:

The general lesson I drew from this work was that it was useful for epistemology to think of communities of knowers, exchanging information and interacting with the world, as (analogous to) distributed computer systems. (Robert Stalnaker, Hendricks and Roy 2010)

The contemporary notion of common knowledge is perhaps the most important concept to emerge from this increased concern for the community of agents. While philosophers are often introduced to this concept through the role that it plays in David Lewis's classic study of convention (Lewis 1969), economists are often introduced to this concept through the writings of economists such a Schelling (1980) and Aumann (1999).

Let us now turn our attention to the papers that are contained in this volume. At least two of the papers in this volume - "Reasons for (prior) belief in Bayesian epistemology" and "The Interference Problem for the Betting Interpretation of Degrees of Belief" - concern issues surrounding subjective probabilities of the sort mentioned previously. A significant amount of work in formal epistemology is based on the assumption that the rational agent has a credal state and that this credal state can be represented as a probability measure. Such an assumption can be motivated in various ways, e.g., the Dutch book argument (Ramsey 1931). In addition to these synchronic constraints on rational credences, diachronic constraints on the relationship between supposing and learning are imposed in much of the work in Bayesian epistemology.

Bayesian epistemologists often start with the assumption that if the rational agent's degree of belief in hypothesis $H$, before learning $E$, is representable as $p(H)$, then its degree of belief in $H$ upon learning $E$ should be representable as $p(H \mid E)$. Since Bayesian epistemology is equipped with a rule for updating beliefs in light of new evidence, it seems natural to wonder if Bayesian epistemology might serve as an adequate foundation for scientific rationality. Some of the most prominent difficulties surrounding such a proposal concern the lack of constraints on the agent's degree of belief in the hypothesis prior to learning the evidencesince the agent's credal state after learning $E$ is assumed to be representable as $p(-\mid E)$, where $p$ is the prior distribution representing the agent's credal state before learning $E$, there are natural concerns about the extent to which communities of such agents can achieve consensus of the sort that might be expected in science. In "Reasons for (prior) belief in Bayesian epistemology", Franz Dietrich 
and Christian List extend some of the concerns of traditional epistemology-in particular the concern that the agent's beliefs be justified-to account for the way in which some prior distributions might be distinguished as reasonable or justified.

Perhaps there are compelling ways to motivate the aforementioned assumptions on rational credences without presupposing anything substantive about the way in which credences are to be measured, but this would seem to be a significant departure from Ramsey's own views:

The subject of our inquiry is the logic of partial belief, and I do not think that we can carry it far unless we have at least an approximate notion of what partial belief is, and how, if at all, it can be measured. (Ramsey 1931)

Following Ramsey, and despite issues of the sort that are considered in Seidenfeld et al. (1990), it is now common to assume that credences can be measured as fair betting odds. In "The Interference Problem for the Betting Interpretation of Degrees of Belief", Lina Eriksson and Wlodek Rabinowicz examine cases in which, roughly speaking, the suggested betting-rate approach might interfere with the very thing that it is supposed to be measuring. In such cases the betting rate interpretation of credences appears to be untenable. The interference problem considered by Eriksson and Rabinowicz is reminiscent of various issues surrounding the "epistemic value of the menu" phenomena discussed by Sen (1993) in the context of a general account of rational choice and by Rott (2004) in the application of such an account to work on belief revision.

As discussed previously, a considerable amount of research has been done on the extent to which human agents deviate from what is required by standard accounts of rationality, e.g., Bayesianism. Although much of this research can be seen as a natural continuation of Kahneman and Tversky's "heuristics and biases" program mentioned above, it is worth noting that some of the most interesting research on the psychology of decision making can be seen as being motivated by concerns that are rather different than the cognitive illusions that informed Kahneman and Tversky's seminal work:

The subjective assessment of probability resembles the subjective assessment of physical quantities such as distance or size. These judgments are all based on data of limited validity, which are processed according to heuristic rules. For example, the apparent distance of an object is determined in part by its clarity. The more sharply the object is seen, the closer it appears to be. This rule has some validity, because in any given scene the more distant objects are seen less sharply than nearer objects. However, the reliance on this rule leads to systematic errors in the estimation of distance. Specifically, distances are often overestimated when visibility is poor because the contours of objects are blurred. On the other hand, distances are often underestimated when visibility is good because the objects are seen sharply. Thus, the reliance on clarity as an indication of distance leads to common biases. Such biases are also found in the intuitive judgement of probability. (Tversky and Kahneman 1974) 
There is much to be said about this highly suggestive passage; e.g., the suggested analogy could be called into question on grounds that in the case of distance there is no question as to what counts as the correct judgment while this is not the case when it comes to probability. ${ }^{1}$ In contrast to the motivations that are suggested in the quoted passage by Kahneman and Tversky, the following passage by Simon suggests a notion of ecological rationality that informs much of Simon's ground-breaking work on decision making dating back to the 1950s:

Human rational behavior (and the rational behavior of all physical symbol systems) is shaped by a scissors whose two blades are the structure of task environments and the computational capabilities of the actor. (Simon 1990)

Interest in ecological rationality and related notions continues to thrive in the "adaptive toolbox" program of Gigerenzer and Selten (2002). In "Fast and Frugal Heuristics: Rationality and the limits of naturalism", Horacio Arló-Costa and Paul Pedersen examine the "normative naturalism" that Gigerenzer and Sturm proposed in their recent discussion of Gigerenzer's research program Gigerenzer and Sturm (2011).

Even if notions like ecological rationality can provide distinct and non-trivial roles for normative as well as descriptive work on decision making, there are other ways of carving out distinct roles for logic and psychology. For example, Isaac Levi has long maintained the importance of distinguishing matters of performance from matters of commitment (Levi 1980; Olsson 2006), an agent's performance with respect to a particular decision might, because of cognitive limitations, fail to satisfy the requirements of the von Neumann-Morgenstern axioms despite that agent's best efforts to satisfy its commitment to those axioms as norms of rational decision making. In "Awareness and Equilibrium", Brian Hill scrutinizes the performance-commitment distinction as it relates to doxastic states.

The papers introduced thus far are concerned primarily with individual agents rather than with communities of such agents. We now turn our attention to a couple of theoretical papers for which the topic of social interactions figures prominently. In "Rulefollowing as coordination: A game-theoretic approach", Giacomo Sillari explains how rule-following as discussed in Wittgenstein's Philosophical Investigations, as well as Kripke's subsequent analysis in Wittgenstein on Rules and Private Language, can be clarified by appealing to Lewis's game-theoretic analysis of social conventions. In "Substantive Assumptions in Interaction: A Logical Perspective", Olivier Roy and Eric Pacuit examine the role of substantive assumptions - which Roy and Pacuit take to be "contingent assumptions about what the players know and believe about each other's choices and information" - in contemporary formal work on the analysis of social interactions. While the previous two papers are primarily theoretical, the next paper reminds us that theoretical work in formal philosophy can be relevant to experimental philosophy. Cristina Bicchieri has for many years been leading the way among philosophers who combine empirical work with concepts from game theory in order to gain a better understanding of social norms. In "Self-serving biases and

\footnotetext{
1 Both de Finetti and Savage famously rejected statistical probabilities.
} 
public justifications in Trust games", Bicchieri and Hugo Mercier examine equality norms and reciprocity norms in the context of their empirical work on trust games.

Finally, as noted at the beginning of this introduction, the conference was also an occasion to present the Synthese Distinguished Paper Award to Professor Brian Skyrms. Like Hintikka, Levi, Putnam and Stalnaker, Professor Skyrms is one of the contemporary philosophers whose ideas have been essential in helping to set the agenda for much of the research that is now done under the heading of formal epistemology. Professor Skyrms won the aforementioned award for his article "Trust, Risk, and the Social Contract" (Skyrms 2008). In "The Core Theory of Subjunctive Conditionals", which is contained in the present volume, Skyrms compares two apparently different theories of subjunctive conditionals: the Adams-Skyrms account, which is based on conditional probabilities, and the Stalnaker-Lewis account that is based on the now familiar "closest possible world" analysis.

\section{References}

Aumann, R. (1999). Interactive epistemology I: Knowledge. International Journal of Game Theory, $28,263-300$.

Ellsberg, D. (1961). Risk, ambiguity, and the Savage axioms. The Quarterly Journal of Economics, 75, 643-669.

Gardenfors, P., \& Sahlin, N.E. (1982). Unreliable probabilities, risk taking, and decision making. Synthese, 53, 361-386.

Gigerenzer, G., Selten, R., (2002). Bounded rationality: the adaptive toolbox. Dahlem Workshop Reports. Cambridge: MIT Press.

Gigerenzer, G., Sturm, T., (2011) How (far) can rationality be naturalized?. Synthese, 1-26.

Hendricks, V., \& Roy, O. (2010). Epistemic logic: 5 Questions. New York: Automatic Press.

Hintikka, J. (1962). Knowledge and belief: An introduction to the logic of the two notions. Ithaca: Cornell University Press.

Jeffrey, R. (1992). Probability and the art of judgment. Cambridge: Cambridge University Press.

Levi, I. (1974). On indeterminate probabilities. Journal of Philosophy, 71, 391-418.

Levi, I. (1980). The enterprise of knowledge. Cambridge: MIT Press.

Lewis, D. (1969). Convention: A philosophical study. Cambridge: Harvard University Press.

Olsson, E. (2006). Knowledge and inquiry: Essays on the pragmatism of isaac levi, Cambridge Studies in Probability, Induction, and Decision Theory. Cambridge: Cambridge University Press.

Ramsey, F.P. (1931). Truth and probability. In R.B. Braithwaite (Ed.), The foundations of mathematics and other logical essays (pp. 156-198). London: Routledge and Kegan Paul.

Rott, H. (2004). Economics and economy in the theory of belief revision. In V. Hendricks, K. Jrgensen, \& S. Pedersen (Eds.), Knowledge contributors synthese library (pp. 57-86). New York: Springer.

Schelling, T. (1980). The strategy of conflict. Cambridge: Harvard University Press.

Seidenfeld, T., Schervish, M., \& Kadane, J. (1990). When fair betting odds are not degrees of belief.PSA: Proceedings of the Biennial Meeting of the Philosophy of Science Association, pp. 517-524.

Sen, A. (1993). Internal consistency of choice. Econometrica, 61(3), 495-521.

Simon, H. (1990). Invariants of human behavior. Annual Review of Psychology, 41(1), 1-19.

Skyrms, B. (2008). Trust, risk, and the social contract. Synthese, 160(1), 21-25.

Tversky, A., \& Kahneman, D. (1974). Judgment under uncertainty: Heuristics and biases. Science, 185, 1124-1131. 